\title{
Design and Simulation by HFSS of a Slim UWB PIFA Antenna
}

\author{
Abdelhakim Elouadih ${ }^{1}$, Ahmed Oulad-Said ${ }^{2}$, Moha Mrabet Hassani ${ }^{1}$ \\ ${ }^{1}$ Department of Physics, Semlalia University of Sciences (FSSM), Marrakesh, Morocco; ${ }^{2}$ Department of Electrical and Telecommu- \\ nications Engineering, Royal Air Academy (ERA), Marrakesh, Morocco. \\ Email: elouadih@gmail.com, a_ouladsaid@hotmail.com, hassani@ucam.ac.ma \\ Received April $7^{\text {th }}, 2013$; revised May $16^{\text {th }}, 2013$; accepted July $5^{\text {th }}, 2013$ \\ Copyright (C) 2013 Abdelhakim Elouadih et al. This is an open access article distributed under the Creative Commons Attribution \\ License, which permits unrestricted use, distribution, and reproduction in any medium, provided the original work is properly cited.
}

\begin{abstract}
This paper describes the design and simulation by High Frequency Structure Simulator (HFSS) of a probe-fed Planar Inverted-F Antenna (PIFA) for the Ultra Wide Band (UWB) personal area networks. The slim antenna presents a height of $2 \mathrm{~mm}$ and a bandwidth of more than $766 \mathrm{MHz}$. This bandwidth was improved by etching a U-slot in the antenna patch. The bandwidth offered then by the antenna is $839 \mathrm{MHz}$ around the resonant frequency of $9 \mathrm{GHz}$. The improvement of bandwidth was accompanied by decreasing in gain and radiation efficiency. The simulation allowed the characterization of the designed antenna and the computing of different antenna parameters like $\mathrm{S}_{11}$ parameter, resonant frequency, bandwidth, radiation efficiency, gain and diagram pattern. The results are very interesting and respect the Federal Communications Commission (FCC) requirements.
\end{abstract}

Keywords: PIFA; HFSS; UWB

\section{Introduction}

UWB is a communication method used in wireless networking to achieve high bandwidth connections with low power utilization. Originally designed for commercial radar systems, UWB technology has potential applications in consumer electronics and Wireless Personal Area Networks (PAN). Ultra-wide band wireless radios send short signal pulses over a broad spectrum. The wide signal allows UWB to commonly support high wireless data rates of $480 \mathrm{Mbps}$ up to $1.6 \mathrm{Gbps}$ at distances up to a few meters. It's the next generation Bluetooth [1]. The use of such technology is increasing and it requires antennas that should have broad working bands. For this, the author tried by this paper to design an antenna for UWB use that should respect the requirements of the American telecommunications regulator FCC. The designed antenna can be mounted on very slim mobile or handset devices giving the antenna thickness equal to $2 \mathrm{~mm}$.

\section{UWB Requirements}

Before Ultra-wideband refers to radio technology with a bandwidth exceeding the lesser of $500 \mathrm{MHz}$ or $20 \%$ of the arithmetic center frequency (called also fractional bandwidth) according to FCC. The FCC authorized the unlicensed use of UWB in the frequency range from 3.1 to $10.6 \mathrm{GHz}$. The FCC power spectral density emission limit for UWB transmitters is $-41.3 \mathrm{dBm} / \mathrm{MHz}$. However, the emission limit for UWB emitters may be significantly lower (as low as $-75 \mathrm{dBm} / \mathrm{MHz}$ ) in other segments of the spectrum [2].

\section{Antenna Description}

The designed antenna has a PIFA configuration. The PIFA consists in general of a ground plane, a top plate element, a feed wire attached between the ground plane and the top plate, and a shorting wire or strip that is connected between the ground plane and the top plate. The antenna is fed at the base of the feed wire at the point where the wire connects to the ground plane. The PIFA is an attractive antenna for wireless systems where the space volume of the antenna for wireless systems where the space volume of the antenna is quite limited. It requires simple manufacturing, since the radiator must only be printed. The addition of a shorting strip allows good impedance match to be achieved with a top plate that is typically less than $\lambda / 4$ long. The resulting PIFA is more compact than a conventional half-wavelength probe-fed patch antenna [3]. As shown in Figures $\mathbf{1}$ to $\mathbf{3}$, the 
designed antenna has a rectangular radiating patch which the length $\mathrm{L}$ is equal to $30 \mathrm{~mm}$ and the width $\mathrm{W}$ equal to $40 \mathrm{~mm}$. The patch is placed at a height h equal to $2 \mathrm{~mm}$ from the ground plan. The ground plan has the same dimensions as the antenna. The patch is matched to the ground plan via a rectangular shorting plate which the width Ws is equal to $1 \mathrm{~mm}$ and has the same height $\mathrm{h}$. The shorting post of usual PIFA types is a good method for reducing the antenna size, but results in narrow impedance bandwidth. It is placed in the (yz) plan at a distance $\mathrm{D}$ equal to $19.5 \mathrm{~mm}$ from the edge center. The feeding point is situated at a distance $\mathrm{p}$ equal to $1 \mathrm{~mm}$ from the rear edge of the patch. The patch is fed by a 50 $\Omega$ wire, a semi-rigid coax with centre conductor that extends beyond the end of the outer conductor is used to form the PIFA feed wire. The outer conductor of the coax is soldered to the edge of a small hole drilled in the ground plane at the feed point. The volume between the radiating plate and the ground plan is filled by the FR4_ epoxy substrate $\mathrm{S}\left(\varepsilon_{\mathrm{r}}=4.4, \operatorname{tg} \delta=0.02\right)$.

\section{Reflection Coefficient}

As given by the HFSS simulator (It uses the finite element model FEM) and shown in Figure 4, the designed antenna presents (along the UWB spectrum band from 3.1 to $10.6 \mathrm{GHz}) 2$ peaks. The first one is around $7 \mathrm{GHz}$, the second is around $8.8 \mathrm{GHz}$. For more precision, a refinement sweep is done around the second peak. The result is presented in Figure 5. We can see a $-10 \mathrm{~dB}$ bandwidth of $766 \mathrm{MHz}$ (from 8545 to $9311 \mathrm{MHz}$ ). It's a width greater than the $500 \mathrm{MHz}$ required by the $\mathrm{FCC}$ and it is compliant to work in FCC band 11 and 12 of the group 4 of UWB allocated bands.

\section{Bandwith Improvement}

Even the found bandwidth respects FCC requirements, the author tried to increase the bandwidth of this antenna without increasing the volume or the height to respect a slim shape. For this, a U-slot was etched on the antenna patch around the feeding point. The Figure 6 and Table 1 give its position and dimensions. The simulation result is shown by Figure 7.

We can also see both peaks. We can notify that the $S_{11}$ of the first peak is reduced to better values. But the interesting improvement is for the second band. The new

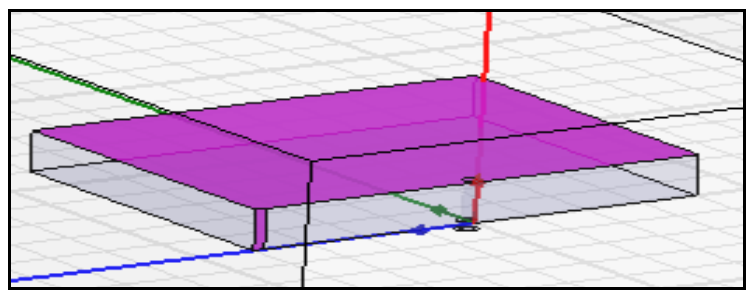

Figure 1. Perspective view of the antenna.

L

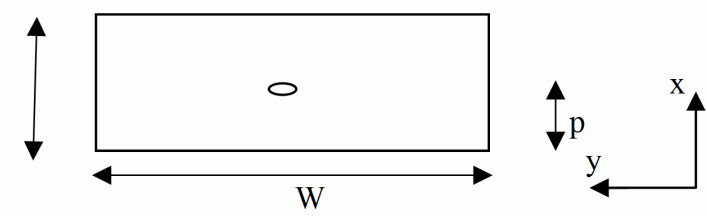

Figure 2. Top view of the antenna.

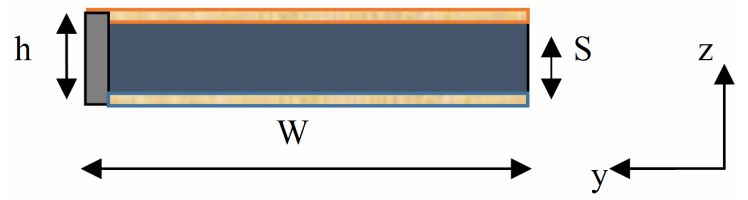

Figure 3. Side view of the antenna.

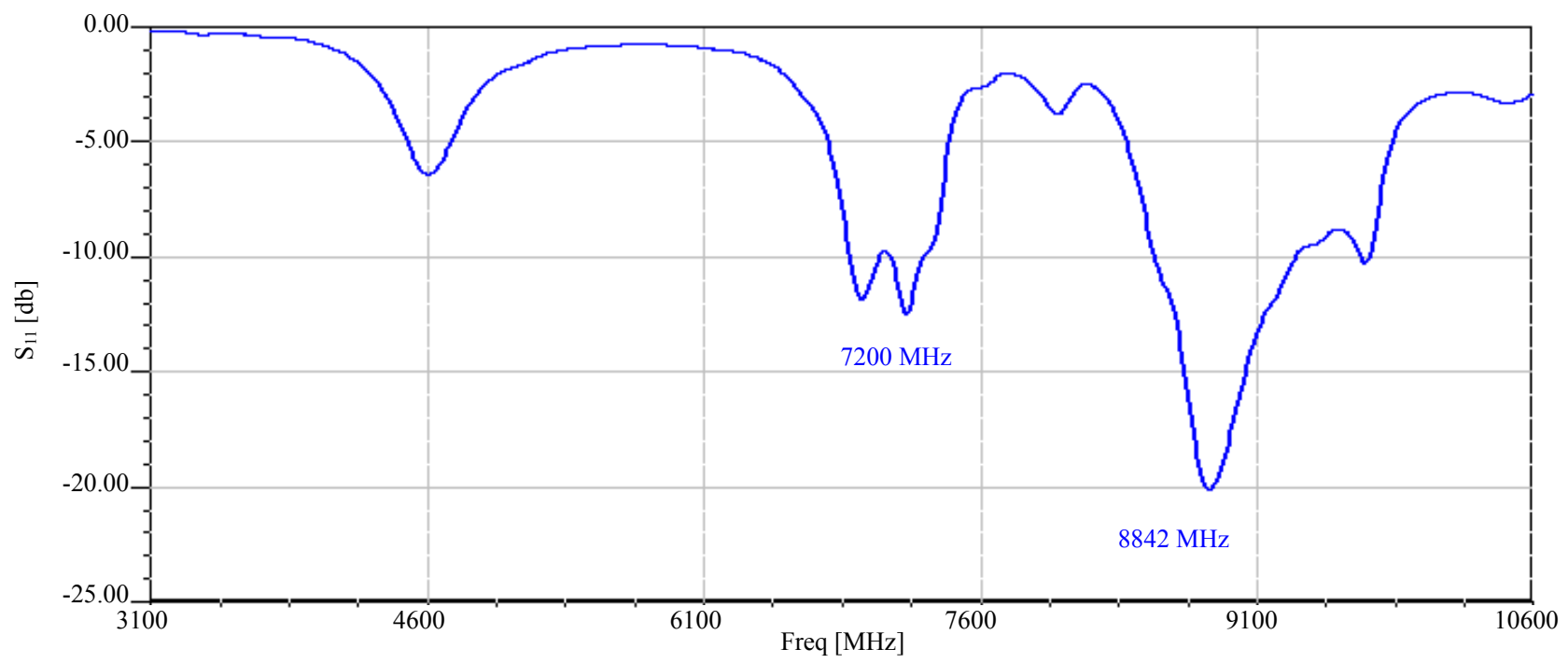

Figure 4. $\mathrm{S}_{11}$ (frequency) in the UWB band. 


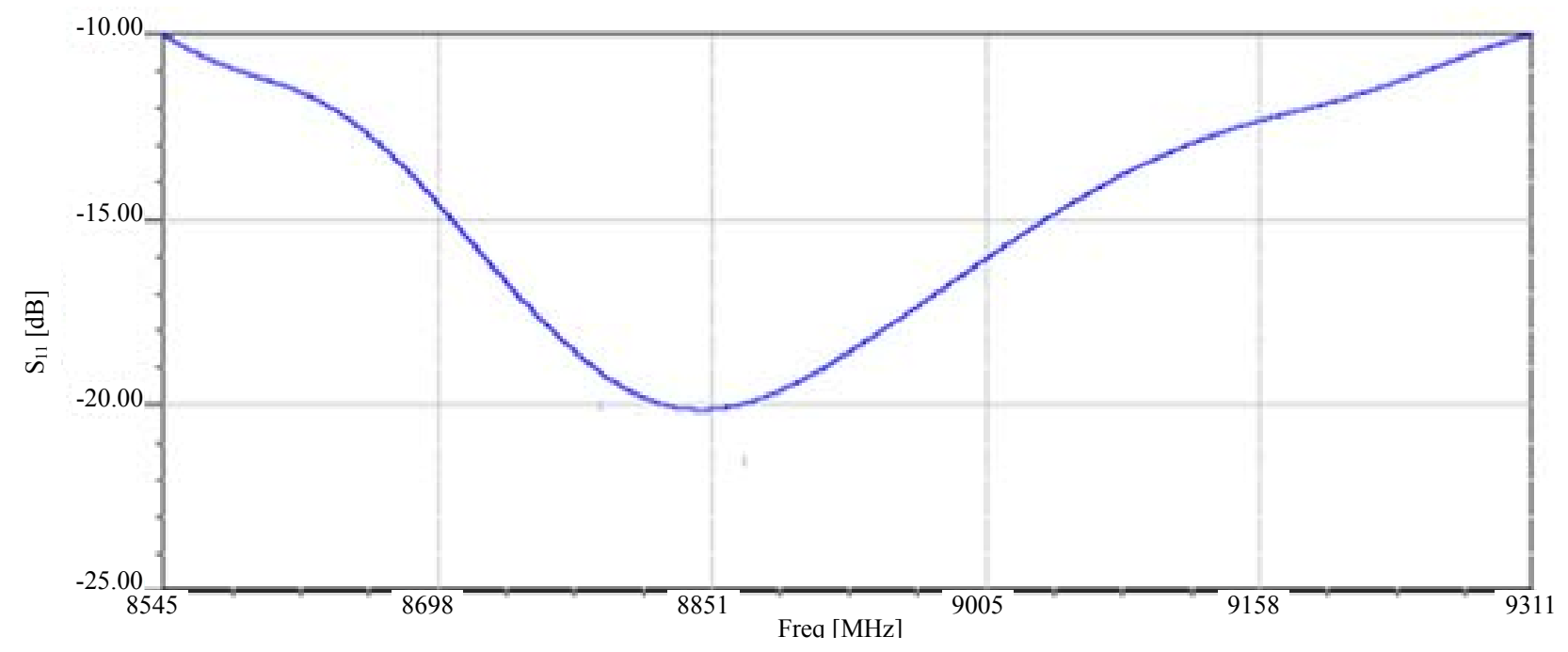

Figure $5 . \mathrm{S}_{11}$ according to frequency in the $8.8 \mathrm{GHz}$ band.

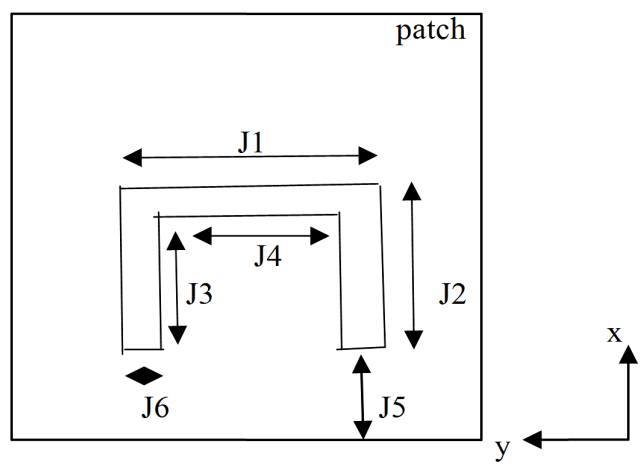

Figure 6. The slot dimensions.

Table 1. The slot dimensions values.

\begin{tabular}{llll}
\hline $\mathrm{J} 1$ & $10 \mathrm{~mm}$ & $\mathrm{~J} 4$ & $8 \mathrm{~mm}$ \\
$\mathrm{~J} 2$ & $4 \mathrm{~mm}$ & $\mathrm{~J} 5$ & $1 \mathrm{~mm}$ \\
$\mathrm{~J} 3$ & $3 \mathrm{~mm}$ & $\mathrm{~J} 6$ & $1 \mathrm{~mm}$ \\
\hline
\end{tabular}

$-10 \mathrm{~dB}$ bandwidth as shown in Figure 7 is equal to 839 $\mathrm{MHz}$ (from 8534 to $9373 \mathrm{MHz}$ ). The band increased by $73 \mathrm{MHz}(10 \%)$. The fractional bandwidth increased from 0.08 to 0.09 .

\section{Simulation Results}

\subsection{The VSWR in the $8.8 \mathrm{GHz}$ Band}

The Figure 8 shows a VSWR min equal to 1.16. The maximum is 1.93 . The whole band presents then a $1.66: 1$ VSWR bandwidth. The VSWR values are then very interesting.

\subsection{The Antenna Parameters}

The Figure 9 summarizes the mean antenna parameters for the selected band as peak directivity, peak gain and radiation efficiency. The antenna presents good values for these parameters especially the gain and the radiation efficiency. We can see from the figure that the value of gain $(9.79 \mathrm{dBi})$, directivity $(11.25 \%)$ are so high as well as the radiation efficiency $(87 \%)$.

\subsection{Radiation Pattern}

The Figures 10 and 11 present respectively the 2D radiation pattern (for the maximum total field) and the 3D radiation pattern. As the pattern shape is concerned. The antenna has no privileged antenna direction even if the field intensity is weak in around phi $= \pm 9^{\circ}$. The maximum field is for theta $=30^{\circ}$. The field maximum intensity becomes greater around phi $= \pm 180^{\circ}$. The total field intensity reaches $23.94 \mathrm{~V} / \mathrm{m}$. The 3D radiation pattern shows no secondary lobes and practically no rear radiation that is interesting to prevent human use from radiating high frequencies waves.

\section{Discussion}

A slim UWB PIFA antenna is then designed with very compliant values of the bandwidth, the gain, the radiation efficiency with a thickness equal to $2 \mathrm{~mm}$. The bandwidth was broaden and increased by $10 \%$. This improvement couldn't be done without influencing other antenna parameters as gain and radiation efficiency. If we compare the new values of antenna parameters after etching slot to whom found before slotting the patch as shown in Figure 12, the gain and directivity lost respectively $0.7 \mathrm{dBi}$ and $0.3 \mathrm{dBi}$. The radiation efficiency decreases from $100 \%$ to $87 \%$. Beside this decrease of parameters, the requirements are yet respected and we have a margin to improve more and more bandwidth viewing 


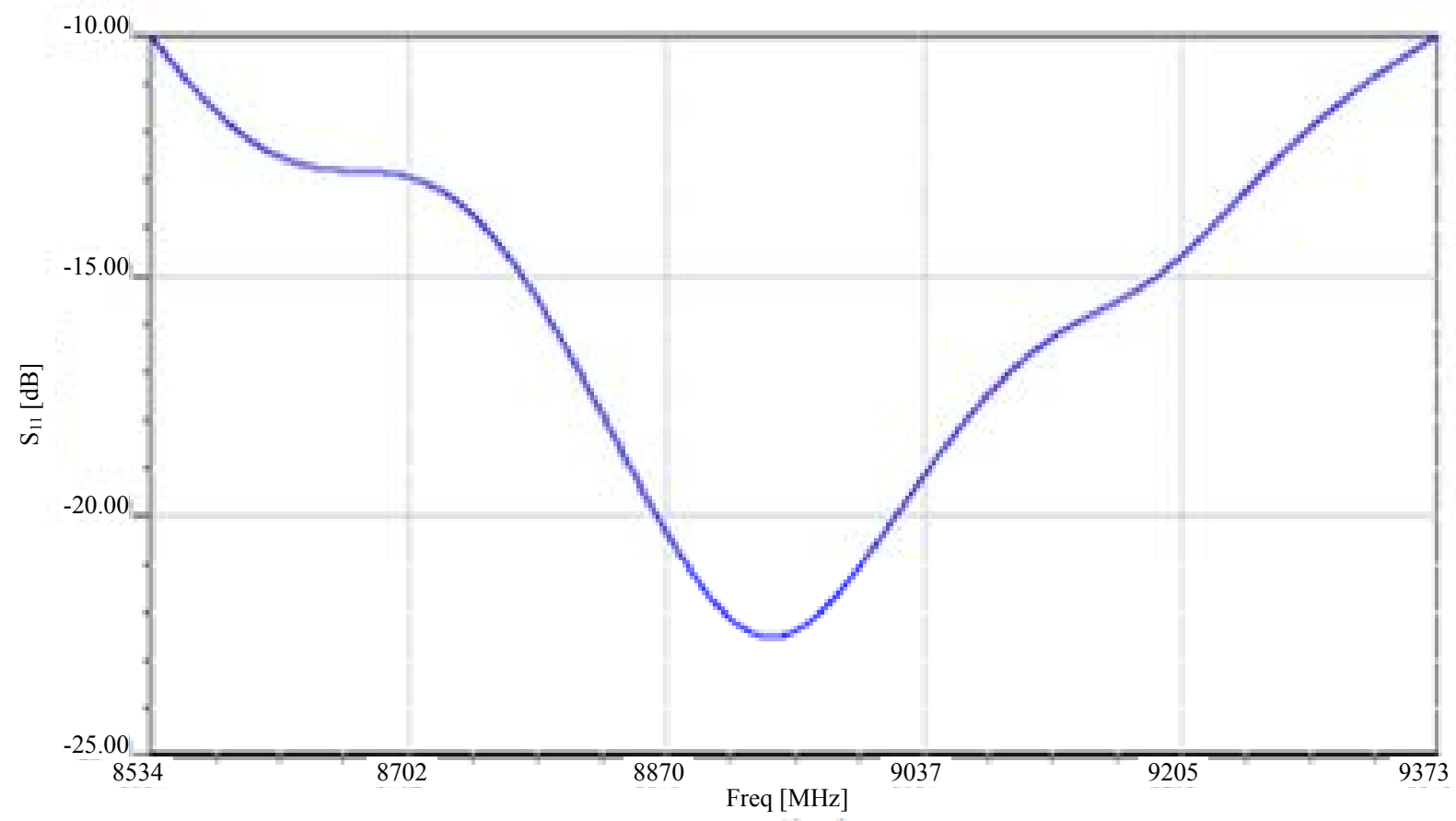

Figure 7. $S_{11}$ according to frequency in the $8.8 \mathrm{GHz}$ band (with slotted patch).

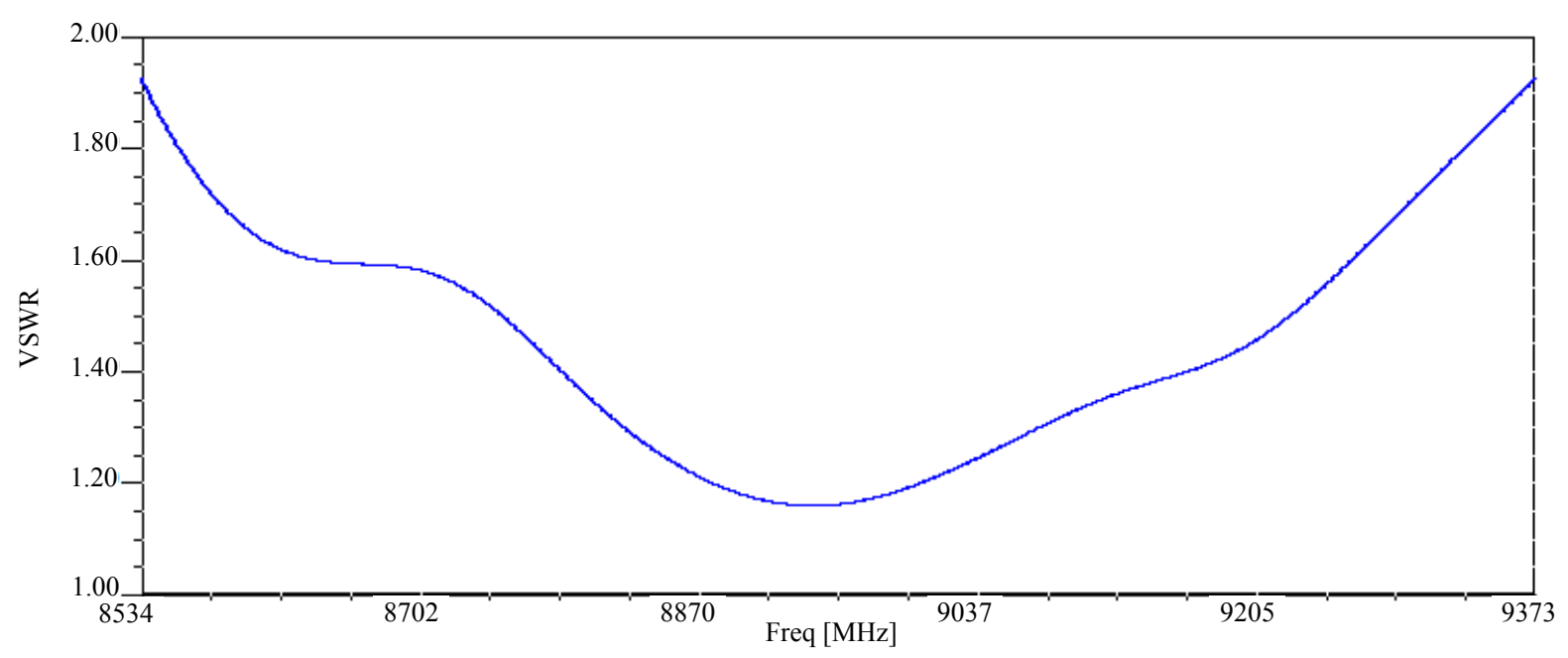

Figure 8. VSWR according to frequency in the $8.8 \mathrm{GHz}$ band.

\begin{tabular}{|c|c|c|c|}
\hline \multicolumn{4}{|c|}{ Antenna Parameters: } \\
\hline & Quantity & Value & Units \\
\hline & Max U & 0.76052 & $\mathrm{~W} / \mathrm{sr}$ \\
\hline & Peak Directivity & 11.254 & \\
\hline & Peak Gain & 9.7914 & \\
\hline & Peak Realized Gain & 9.5572 & \\
\hline & Radiated Power & 0.84925 & W \\
\hline & Accepted Power & 0.97608 & w \\
\hline & Incident Power & 1 & $w$ \\
\hline & Radiation Efficiency & 0.87006 & \\
\hline & Decay Factor & 0 & \\
\hline
\end{tabular}

Figure 9. The antenna parameters as given by simulation. 


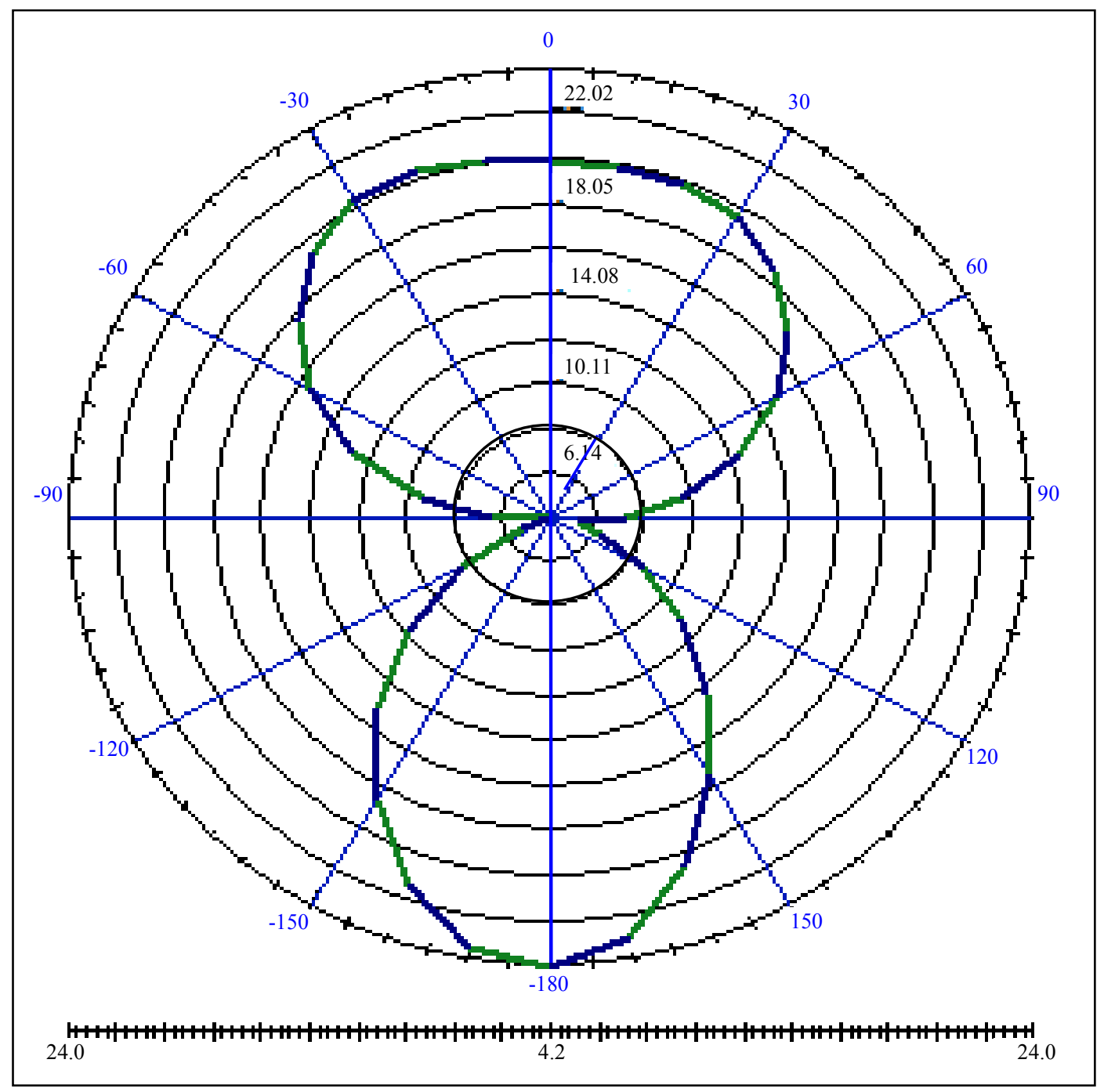

Figure 10. 2D radiation pattern for E-Field (for theta $=30^{\circ}$ ).

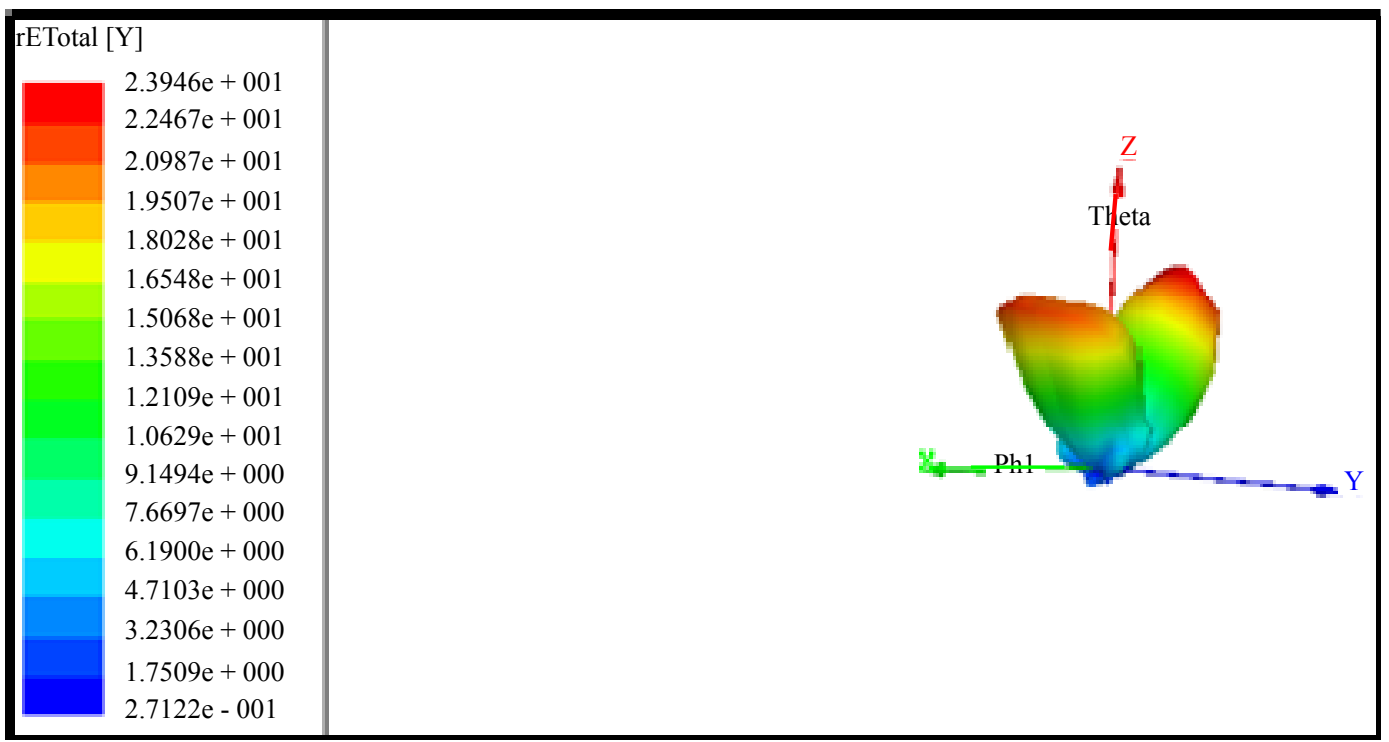

Figure 11. The 3D radiation pattern. 


\begin{tabular}{|c|c|c|c|}
\hline \multicolumn{4}{|c|}{ Antenna Parameters: } \\
\hline & Quantity & Value & Units \\
\hline & $\operatorname{Max} U$ & 0.95076 & $W / s r$ \\
\hline & Peak Directivity & 11.962 & \\
\hline & Peak Gain & 12.085 & \\
\hline & Peak Realized Gain & 11.948 & \\
\hline & Radiated Power & 0.99879 & W \\
\hline & Accepted Power & 0.98864 & W \\
\hline & Incident Power & 1 & W \\
\hline & Radiation Efficiency & 1.0103 & \\
\hline & Decay Factor & 0 & \\
\hline
\end{tabular}

Figure 12. The antenna parameters before slotting the patch.

this interest of our application. In comparison with precedent works [4-12] that have the same goal designing UWB for different band groups, the designed antenna presents a bandwidth litter but a very high gain and radiation efficiency.

\section{Conclusion}

In this paper, a slim antenna was designed for the UWB application with a band of $839 \mathrm{MHz}$ around $8.8 \mathrm{GHz}$. The antenna parameters are very compliant for this application. The bandwidth was improved with a tolerable degradation in some of antenna parameters. The designed antenna presents very significant values of gain and radiation efficiency and could be a very compliant solution for the applications that need gain and directivity such locating and tracking application (anti-collision vehicle radar or imaging radar). The most important application of the ultarwideband is the data transmission using spread spectrum allowing high data speed without interfering with conventional narrowband and carrier wave used in the same frequency band. The designed antenna can be used in different applications and it is then a succeeded trade-off that respects the FCC UWB requirements.

\section{REFERENCES}

[1] M. Bradly, "UWB in about.com guide," 2013. http://compnetworking.about.com/od/networkprotocols/g/ ultra_wide_band.htm

[2] Federal Communication Commission, "Washington D.C. First Report and Order, Revision of Part 15 of the Commission's Rule Regarding Ultra Wideband Transmission Systems," FCC, Washington DC, 2002, pp. 2-48.

[3] K. L. Virga and Y. Rahmat-samii, "Low-Profile Enhanced Bandwidth PIFA for Wireless Communications Packaging," IEEE Transactions on Microwave Theory and Techniques, Vol. 45, No. 10, 1997, pp1879-1888. doi: $10.1109 / 22.641786$

[4] G. Tatsis, V. Raptis and P. Kostarakis, "Design and Meas- urements of Ultra-Wideband Antenna," International Journal of Communications, Network and System Sciences, Vol. 3, No. 2, 2010, pp. 116-118. doi:10.4236/ijens.2010.32017

[5] Y. Yao, W. Chen, B. Huang, Z. Fen and Z. Zhang, "Analysis and Design of Tapered Slot Antenna for UltraWideband Applications," Tsinghua Science and Technology Journal, Vol. 14, No. 1, 2009, pp. 1-6.

[6] S. Jiao, N. Ge, J. Lu and M. Jiang, "Monopole Crescent Elliptical Antenna with Band-Notched Characteristics for UWB Applications," Tsinghua Science and Technology Journal, Vol. 14, No. 4, 2009, pp. 460-464.

[7] S. M. Naveen, R. M. Vani and P. V. Hunagund, "Compact Wideband Rectangular Monopole Antenna for Wireless Applications," Wireless Engineering and Technology, Vol. 3, No. 4, 2012, pp. 240-243. doi:10.4236/wet.2012.34034

[8] C. Lee, H. Huang, C. Yang and C. Wang, "An Experimental Study of the Printed-Circuit Elliptic Dipole Antenna with 1.5 - $16 \mathrm{GHz}$ Bandwidth," International Journal of Communications, Network and System Sciences, Vol. 1, No. 4, 2008, pp. 295-300. doi:10.4236/ijens.2008.14036

[9] A.Shaker, S. H. Zainud-Deen, K. R. Mahmoud and S. M. Ibrahem, "Compact Bluetooth/UWB Antenna with MultiBand Notched Characteristics," Journal of Electromagnetic Analysis and Applications, Vol. 3, No. 12, 2011, pp. 512-518. doi:10.4236/jemaa.2011.312078

[10] H. T. Chattha, Y. Huang, Y. Lu and X. Zhu, "Further Bandwidth Enhancement of PIFA by Adding a Parasitic Element," Proceedings of IEEE Antennas \& Propagation Conference, Loughborough, 16-17 November 2009, pp. 213-216. doi:10.1109/LAPC.2009.5352441

[11] H. T. Chattha, Y. Huang, M. K. Ishfaq and S. J. Boyes, "Bandwidth Enhancement Techniques for Planar Inverted-F Antenna," Microwaves, Antennas and Propagation Magazine, Vol. 5, No. 15, 2011, pp. 1872-1879.

[12] H. T. Chattha, Y. Huang, Y. Lu and X. Zhu, "UWB Planar Inverted-F Antenna (PIFA) with Differential Feeding Technique," Proceedings of the IEEE International Conference on Ultra-Wideband, Nanjing, 20-23 September 2010, pp. 1-4. doi:10.1109/ICUWB.2010.561531510 